\title{
CBF Reactivity in Hypotensive and Normotensive Preterm Infants
}

\author{
DULIP JAYASINGHE, A. BRYAN GILL, AND MALCOLM I. LEVENE \\ Division of Paediatrics and Child Health [D.J., M.I.L.], and Peter Congdon Neonatal Unit [A.B.G.], \\ Clarendon Wing, The General Infirmary at Leeds, Leeds LS2 9NS, United Kingdom
}

\begin{abstract}
Perinatal distress in the preterm neonate, and the consequent loss of cerebrovascular autoregulation, has been implicated in the pathogenesis of neonatal cerebral lesions. A component of this distress is thought to be hypotension. We examined the autoregulatory capacity of hypotensive and normotensive infants using the ${ }^{133} \mathrm{Xe}$ technique to measure cerebral blood flow. Global CBF was measured during only normotension in 5 infants, and during both hypotension and normotension in 11 infants. All the infants were ventilated and blood pressure was measured using an intra-arterial catheter. Fourteen CBF measurements were made on the normotensive infants. Forty-seven CBF measurements were made on the hypotensive infants, 34 measurements during hypotension and 13 during normotension. The global CBF of the normotensive and hypotensive infants were 13.3 and $13.6 \mathrm{~mL} /$ $100 \mathrm{~g} / \mathrm{min}$, respectively. The mean arterial blood pressure (MABP)-CBF reactivity $(95 \% \mathrm{CI})$ of the normotensive and hypotensive infants were $1.9 \%(-0.8 \%$ to $4.7 \%) / \mathrm{mm} \mathrm{Hg}$ and $1.9 \%(0.8 \%$ to $3.0 \%) / \mathrm{mm} \mathrm{Hg}$, respectively. The $\mathrm{CO}_{2}-\mathrm{CBF}$ reactivity $(95 \% \mathrm{CI})$ of the normotensive and hypotensive infants was
\end{abstract}

\section{ABSTRACT}

$11.1 \%(6.8 \%$ to $15.5 \%) / \mathrm{KPa} \Delta \mathrm{PaCO}_{2}$ and $4.1 \%$ (-5.0\% to $14.1 \%) / \mathrm{KPa} \Delta \mathrm{PaCO}_{2}$. The implications of these calculated $\mathrm{CBF}$ reactivities is that normotensive infants may have intact autoregulation but with a diminished response to fluctuations in $\mathrm{PaCO}_{2}$. The hypotensive infants appear to have attenuated or absent autoregulation with little or no response in CBF to changes in $\mathrm{PaCO}_{2}$. (Pediatr Res 54: 848-853, 2003)

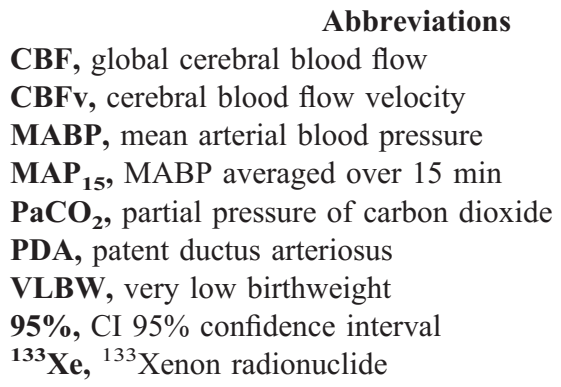

Hypotension in the sick preterm infant has been implicated as one causative factor in the pathogenesis of a number of serious conditions including intraventricular hemorrhage (IVH) (1), periventricular leukomalacia (PVL) (2), necrotizing enterocolitis (3), and developmental delay in preterm infants (4).

It is thought that perinatal asphyxia combined with hypotension leads to a loss of cerebrovascular autoregulation, which may lead to a pressure passive cerebral circulation (5). In this state, abrupt elevations in systemic blood pressure may be transmitted to the fragile vessels of the germinal matrix, possibly resulting in intraventricular hemorrhage. Historically, systemic hypotension was thought to lead to under perfusion of watershed areas, which then underwent infarction and cystic

Received March 13, 2001; accepted Jan 14, 2003.

Correspondence: M.I. Levene, Division of Paediatrics and Child Health, D Floor, Clarendon Wing, The General Infirmary at Leeds, Leeds LS2 9NS, United Kingdom; e-mail: medmil@south-ol.novell.leeds.ac.uk.

DOI: 10.1203/01.PDR.0000088071.30873.DA necrosis, resulting in PVL (6). Thus, absent autoregulation may be central to many causes of perinatal CNS pathology.

The work of Tyszczuk et al. among others, has led to the re-evaluation of the absent autoregulation hypothesis (7). They found no significant difference between the cerebral blood flow $(\mathrm{CBF})$ of normotensive infants and that of hypotensive infants. Furthermore, a number of studies have found no association between hypotension and PVL $(2,8,9)$. More recently, it was found that $53 \%$ of ventilated preterm infants had evidence of impaired autoregulation (10) and Boylan et al. have identified abnormalities in the autoregulatory capacity of preterm infants (11). Only in the work of Tyszczuk was the influence of hypotension analyzed in the etiology of impaired autoregulation.

Changes in arterial carbon dioxide are a major mediator of CBF variation in the normal preterm infant $(12,13)$. It has been suggested that blunting of this normal variation in vessel caliber is associated with cerebral lesions (13).

CBF may be measured using different modalities. If a gold standard for measurement could be said to exist, it might be radioactive microsphere method (14). The i.v. ${ }^{133} \mathrm{Xe}$ technique 
method is a good compromise, in which global CBF may be measured accurately over $15 \mathrm{~min}$, and compares with both the radioactive microsphere method (in animals) (15) and other modalities $(16,17)$.

The aim of this study was to test the hypothesis that CBF reactivity to changes in $\mathrm{MABP}$ or $\mathrm{PaCO}_{2}$ is lost in hypotensive, ventilated, preterm infants.

\section{METHOD}

Infants were eligible to enter the study if they were mechanically ventilated and had an intra-arterial catheter, either umbilical or peripheral. The indwelling arterial lines were calibrated before each measurement of CBF. All infants were sedated with a diamorphine infusion and, if clinically indicated, some received muscle paralysis with pancuronium bromide. Written informed consent was obtained from one or both parents and the hospital research ethics committee approved the study. Radiation dosage was kept well within accepted national guidelines.

The infant's physiologic parameters were displayed on a Hewlett Packard physiologic monitoring system, Merlin 66S (Hewlett Packard, Palo Alto, CA, U.S.A.). This was connected to a continuous monitoring system (MARY system, Meadowbank Medical Systems Ltd, Loughborough, U.K.) that recorded second-to-second data.

The infants were enrolled in a study investigating the effect of treating hypotension on CBF. The sequence of events for measuring $\mathrm{CBF}$ and $\mathrm{MAP}_{15}$ are outlined in Fig. 1. During the period of this study it was the policy of this unit to maintain MABP above the 10th centile (BPmin) for birthweight and postnatal age (18). Hypotension was treated in a stepwise manner, and following initiation of treatment, thirty minutes was allowed for stabilization of MABP. The initial intervention was the use of $4.5 \%$ human albumin solution infused over 30

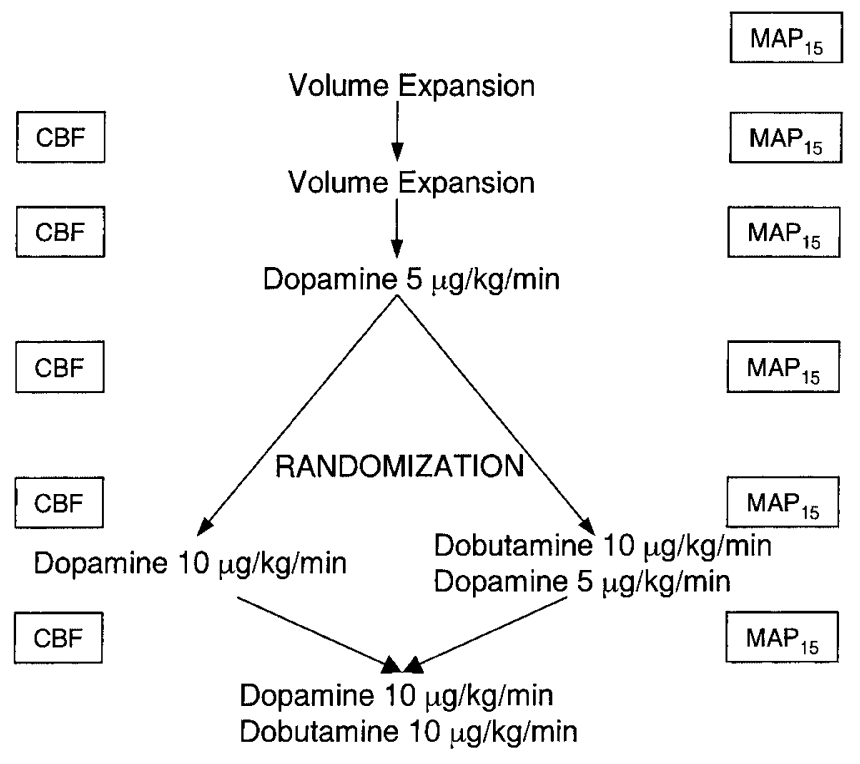

Figure 1. The hypotension treatment protocol is illustrated. A maximum of 5 CBF measurements were obtained, before and after initiation or escalation of treatment. The duration of a CBF measurement is $15 \mathrm{~min}$, during which MABP is continuously measured and averaged for the $15-\mathrm{min}$ period $\left(\mathrm{MAP}_{15}\right)$. min, which may have been repeated once. If volume expansion was ineffective, a dopamine infusion was started at a dose of 5 $\mu \mathrm{g} / \mathrm{kg} / \mathrm{min}$. After stabilization, and if still hypotensive, the infant was randomized to either increase of dopamine to 10 $\mu \mathrm{g} / \mathrm{kg} / \mathrm{min}$ or the addition of dobutamine at a dose of 10 $\mu \mathrm{g} / \mathrm{kg} / \mathrm{min}$. If still hypotensive, either the dopamine dose was increased to $10 \mu \mathrm{g} / \mathrm{kg} / \mathrm{min}$ or dobutamine was added at 10 $\mu \mathrm{g} / \mathrm{kg} / \mathrm{min}$, the cross over treatment. If an infant had resistant hypotension, then by the end of the treatment protocol, it should be receiving both dopamine and dobutamine at doses of $10 \mu \mathrm{g} / \mathrm{kg} / \mathrm{min}$.

Before and $30 \mathrm{~min}$ after intervention, the $\mathrm{CBF}$ was measured using the i.v. ${ }^{133} \mathrm{Xe}$ technique. This has been described before (16) but is outlined briefly here. $30 \mathrm{MBq} / \mathrm{kg}$ of the radionuclide ${ }^{133} \mathrm{Xe}$ was injected as a peripheral, $1 \mathrm{~mL}$ i.v. bolus. Collimated Sodium-Iodide gamma-detectors were used to measure activity over the upper right chest wall and the temporofrontal region of the infant's skull for $15 \mathrm{~min}$. Data from detectors were converted by an analogue to digital converter and stored on a laptop computer (Cortexplorer, Vertec Scientific Limited, U.K.). Background activity was measured for between 2 and 5 min before injecting the Xe radioisotope. The intra-individual variation of $\mathrm{CBF}$ using the ${ }^{133} \mathrm{Xe}$ technique is between $10 \%$ and $15 \%$ (19). One investigator (DJ) recorded the CBF measurements. The maximum radiation dosage of Xenon per measurement administered to each infant is shown in Table 1. No baby received more than $3.5 \mu \mathrm{Sv}$, in contrast to one chest x-ray that delivers a dose of $20 \mu \mathrm{Sv}$.

The CBF was calculated over a 15 -min period from the point that the chest count fell to $20 \%$ of the maximum. This value was used to minimize contamination of the cranial counter from activity in the upper airway. At the end of a CBF measurement arterial blood was withdrawn to measure $\mathrm{PaCO}_{2}$. The MABP during the $\mathrm{CBF}$ measurement was averaged to yield a mean over $15 \min \left(\mathrm{MAP}_{15}\right)$.

If the $\mathrm{MAP}_{15}$ was less than or equal to the BPmin during any of the $\mathrm{CBF}$ recordings then the infant was deemed to be hypotensive. Alternatively, the infant is designated normotensive if the $\mathrm{MAP}_{15}$ was above BPmin before and after treatment. Table 1 contains clinical details of the infants in the two groups, including the level of sedation, inotrope requirement, total number of $\mathrm{CBF}$ measures and the maximum dosage of radiation given.

Statistics. The Mann-Whitney U test was applied for comparisons between groups, since the data were not normally distributed. A $p$ value of less than 0.05 was deemed to represent significance.

Multiple regression was used to assess CBF reactivity because it allowed modeling of the simultaneous effects of predictor variables. To ensure a homogeneous variance the natural logarithm of the $\mathrm{CBF}$ was used as the dependent variable and the $\mathrm{MAP}_{15}$ and $\mathrm{PaCO}_{2}$ as the independent variables. The study made use of repeated measures on each infant. To allow for this, dummy variables were used, one for each of $\mathrm{n}$ infants in each group (D1-Dn) (20). This produces a regression equation of the form :

The anti-logarithm of the regression coefficients $\beta_{1}$ and $\beta_{2}$ provide the percentage values of $\mathrm{MAP}_{15}$ and $\mathrm{CO}_{2}-\mathrm{CBF}$ reac- 
Table 1. Clinical details of infants enrolled into the study

\begin{tabular}{|c|c|c|c|c|c|c|c|c|c|}
\hline Infant & BWt (g) & $\mathrm{Hb}(\mathrm{g} / \mathrm{dL})$ & $\begin{array}{l}\text { Glucose } \\
(\mathrm{mmol} / \mathrm{L})\end{array}$ & Paralysis & CBF (n) & $\begin{array}{l}\text { Max dosage } \\
\text { MBq }(\mu \mathrm{Sv})\end{array}$ & Treatment level & $\begin{array}{c}\text { Most severe } \\
\text { cranial ultrasound }\end{array}$ & Outcome \\
\hline 1 & 1260 & 15.2 & $1.9,2.3$ & Yes & 5 & $57.5(2.9)$ & DA5, 10 & $?$ & Discharged \\
\hline 2 & 760 & 13.8 & $?$ & Yes & 5 & $28(1.4)$ & DA5, 10, Dob10 & Bulky choroids & Care withdrawn \\
\hline 4 & 660 & 13.4 & 5.0 & Yes & 5 & $21(1.1)$ & V, DA5, Dob10 & Ventricular Infarct & Care withdrawn \\
\hline 5 & 600 & 14.9 & $?$ & Yes & 3 & $21.5(1.1)$ & $\mathrm{V}, \mathrm{DA} 5$ & ? & Discharged \\
\hline 6 & 540 & 18.1 & $?$ & No & 4 & $22.5(1.2)$ & V, DA5, Dob10 & Grade 2 & Care withdrawn \\
\hline 9 & 620 & 16.6 & $5.9,10.3$ & No & 5 & $26(1.3)$ & V, DA5, Dob10 & Left grade 2 & Discharged \\
\hline 10 & 1200 & 17.4 & 5.9 & No & 3 & $53(2.6)$ & DA5, Dob10 & $?$ & Discharged \\
\hline 11 & 1100 & 17.9 & 4.4 & Yes & 5 & $36(1.8)$ & DA5, 10 , Dob10 & Bilateral ED & Discharged \\
\hline 12 & 1000 & 12.2 & $?$ & No & 4 & $49(2.5)$ & $\mathrm{V}$ & Bilateral ED & Care withdrawn \\
\hline 13 & 1040 & 18.3 & $?$ & Yes & 2 & $40(2.0)$ & V & Normal & Discharged \\
\hline 14 & 1355 & 12.0 & $?$ & No & 2 & $57(2.8)$ & V & Normal & Discharged \\
\hline
\end{tabular}

Clinical details of all patients: BWt, birth weight; $\mathrm{Hb}$, hemoglobin and glucose at the time of CBF measurement; Paralysis with pancuronium bromide; $\mathrm{CBF}$, number of CBF measurements; Maximum dosage given for one CBF measurement in $\mathrm{MBq}(\mu \mathrm{Sv})$; Treatment level (V, volume expansion; DA and Dob, dopamine and dobutamine dosage in $\mu \mathrm{g} / \mathrm{kg} / \mathrm{min}$.); Most severe cranial ultrasound scan graded by the system of Papille et al. (ED echodensity).

tivities, respectively. Confidence limits for $\mathrm{MAP}_{15}-\mathrm{CBF}$ and $\mathrm{PaCO}_{2}$-CBF reactivity were calculated using the $t$ distribution. One degree of freedom was subtracted from the total number of observations for each factor estimated.

$\boldsymbol{C B F}$ reactivity. The calculated $\mathrm{CBF}-$ reactivity is the percentage by which $\mathrm{CBF}$ varies per unit variation of another factor (e.g. $\mathrm{MAP}_{15}$ or $\mathrm{PaCO}_{2}$ ). When the $95 \%$ confidence interval encompasses zero there may be no change in $\mathrm{CBF}$ for variation in another factor. In the case of $\mathrm{MAP}_{15}-\mathrm{CBF}$ reactivity, no change in $\mathrm{CBF}$ against fluctuating $\mathrm{MAP}_{15}$ implies intact autoregulation (21). In contrast $0 \% \mathrm{PaCO}_{2}$-CBF reactivity implies absence of the normal change in vessel caliber in response to fluctuating $\mathrm{PaCO}_{2}$ (22).

\section{RESULTS}

Sixty-one CBF recordings were obtained from sixteen infants over 23 mo. The infants were divided into two groups based upon their MAP15 at the time of CBF acquisition. None of the infants appear in both groups.

All $14 \mathrm{CBF}$ measurements on the normotensive infants (infants 12-16) were acquired while $\mathrm{MAP}_{15}$ was greater than BPmin. Four infants (infants 12-15) were treated with volume for poor peripheral perfusion, low urine output or metabolic acidosis, and the CBF measured before and after. The fifth infant (infant 16) was treated inadvertently for hypotension while normotensive, the $\mathrm{MAP}_{15}$ being greater than BPmin.

During 34 of the $47 \mathrm{CBF}$ measurements performed on the hypotensive infants (infants 1-11) $\mathrm{MAP}_{15}$ was less than BPmin. During the remaining 13 measurements, the infants were normotensive.

Table 2 contains clinical data about the two groups. The two groups differ significantly in two of the parameters, $\mathrm{MAP}_{15}$ and postnatal age. The upper range of the $\mathrm{MAP}_{15}$ in the hypotensive infants has values measured after treatment, when some infants were rendered normotensive.

The changes in physiologic parameters between CBF measurements are detailed in Table 3. The interval represents the
Table 2. Demographic details for the normotensive and hypotensive infants as median (range) values

\begin{tabular}{lccl}
\hline & $\begin{array}{c}\text { Normotensive } \\
(5 \text { infants })\end{array}$ & $\begin{array}{c}\text { Hypotensive } \\
\text { (11 infants) }\end{array}$ & $p$ value* \\
\hline Birthweight $(\mathrm{g})$ & $1060(1000$ to 1355$)$ & $720(540$ to 2100$)$ & 0.26 \\
Gestation (weeks) & $28(26$ to 29$)$ & $26(24$ to 32$)$ & 0.26 \\
Postnatal age (hours) & $43(5$ to 94$)$ & $13(3$ to 61$)$ & 0.02 \\
$\mathrm{MAP}_{15}(\mathrm{mmHg})$ & $40(27$ to 44$)$ & $24(19$ to 51$)$ & 0.0001 \\
$\mathrm{PaCO}_{2}(\mathrm{KPa})$ & $5.6(3.9$ to 12.3$)$ & $4.9(2.3$ to 6.9$)$ & 0.15 \\
$\mathrm{CBF}(\mathrm{ml} / 100 \mathrm{~g} / \mathrm{min})$ & $13.3(8.6$ to 23.1$)$ & $13.6(7.0$ to 39.7$)$ & 0.86 \\
\hline
\end{tabular}

$\mathrm{PaCO} 2(\mathrm{mmHg})=\mathrm{KPa} * 0.133)$.

* Normotensive versus hypotensive groups.

time between serial CBF measurements. The step change in $\mathrm{MAP}_{15}$ between CBF measurements is given both as absolute values and the percentage change, relative to the previous value.

Normotensive group. The $\mathrm{MAP}_{15}$-CBF reactivity and $95 \%$ confidence limits for the normotensive group were 1.9\% $(-0.8 \%$ to $4.7 \%) / \mathrm{mm} \mathrm{Hg} \Delta \mathrm{MAP}_{15}$. The $\mathrm{CO}_{2}-\mathrm{CBF}$ reactivity with $95 \%$ confidence limits is $11.1 \%(6.8 \%$ to $15.5 \%) / \mathrm{KPa}$ $\triangle \mathrm{PaCO}_{2}$. The lower confidence interval of the $\mathrm{MAP}_{15}-\mathrm{CBF}$ encompasses zero and that of the $\mathrm{CO}_{2}$-CBF reactivity does not (Fig. $2 A$ and $B$ ).

The analysis was repeated excluding the infant who received dopamine (infant 16), the calculated reactivities were similar; $\mathrm{MAP}_{15}{ }^{-\mathrm{CBF}}$ reactivity $5.0 \%(-5.6 \%$ to $7.0 \%) / \mathrm{mm} \mathrm{Hg} \Delta \mathrm{MAP}_{15}$, and $\mathrm{CO}_{2}$-CBF reactivity $9.5 \%(3.4 \%$ to $15.5 \%) / \mathrm{KPa} \Delta \mathrm{PaCO}_{2}$.

Hypotensive group. The $\mathrm{MAP}_{15}-\mathrm{CBF}$ reactivity with $95 \%$ confidence limits is $1.9 \%(0.8 \%$ to $3.0 \%) / \mathrm{mm} \mathrm{Hg} \Delta \mathrm{MAP}_{15}$. In contrast to the normotensive infants, the lower confidence interval of $\mathrm{MAP}_{15}-\mathrm{CBF}$ reactivity is greater than zero. The $\mathrm{CO}_{2}$-CBF reactivity with $95 \%$ confidence limits are $4.1 \%$ $\left(-5.0 \%\right.$ to $14.1 \%$ ) $/ \mathrm{KPa} \Delta \mathrm{PaCO}_{2}$ (Fig. $2 A$ and $B$ ).

\section{DISCUSSION}

The aim of this study was to assess the influence on CBF of changes in blood pressure in hypotensive, ventilated, preterm 
Table 3. Variation of physiological variables between CBF measurements as the median (range)

\begin{tabular}{|c|c|c|c|}
\hline & Normotension & Hypotension & $p$ value* \\
\hline $\begin{array}{l}\text { Number of CBF measures } \\
\text { (Normotensive/hypotensive) }\end{array}$ & $\begin{array}{c}14 \\
(14 / 0)\end{array}$ & $\begin{array}{c}47 \\
(13 / 34)\end{array}$ & \\
\hline Interval between $\mathrm{CBF}$ & 84 minutes & 90 minutes & 0.50 \\
\hline Absolute $\Delta \mathrm{MAP}_{15}(\mathrm{~mm} \mathrm{Hg})$ & $2(0$ to 9$)$ & $2(0$ to 29$)$ & 0.63 \\
\hline Relative $\Delta \mathrm{MAP}_{15}(\%)$ & $6 \%(0 \%$ to $465 \%)$ & $10 \%(0 \%$ to $109 \%)$ & 0.29 \\
\hline Absolute $\triangle \mathrm{PaCO}_{2}(\mathrm{KPa})$ & $0.0(-8.1$ to 2.1$)$ & $0.0(-2.7$ to 2.7$)$ & 0.80 \\
\hline $\mathrm{MAP}_{15}-\mathrm{BPmin}(\mathrm{mm} \mathrm{Hg})$ & $+10(+1$ to +14$)$ & $-1(-10$ to +24$)$ & $<0.001$ \\
\hline
\end{tabular}

* Normotensive versus Hypotensive groups.

infants. The $\mathrm{MAP}_{15}-\mathrm{CBF}$ reactivity of normotensive and hypotensive infants was $1.9 \% / \mathrm{mm} \mathrm{Hg}$, but the lower confidence interval of the normotensive infants encompassed 0 . The $\mathrm{CO}_{2}-$ $\mathrm{CBF}$ reactivities of the normotensive and hypotensive infants were $11.1 \%$ and $4.1 \% / \mathrm{KPa} \Delta \mathrm{PaCO}_{2}$, respectively. We speculated from our results an impairment of $\mathrm{MAP}_{15}-\mathrm{CBF}$ autoregulation, and attenuation of $\mathrm{PaCO}_{2}$-CBF reactivity in these hypotensive, ventilated preterm infants. The CBF was measured using the i.v. ${ }^{133} \mathrm{Xe}$ technique, which is accepted as a valid tool for measuring the $\mathrm{CBF}$ in both term and preterm infants $(16,23,24)$. The repeated measures design of this study, combined with the need for incorporating simultaneous changes in two factors ( $\mathrm{MAP}_{15}$ and $\left.\mathrm{PaCO}_{2}\right)$, necessitates the type of analysis used (25).

Others have used Doppler ultrasound to measure $\mathrm{CBFv}$ $(26-29)$. While there is close agreement between ${ }^{133} \mathrm{Xe}$ technique measured global CBF and CBFv (16), Doppler ultrasound is limited by the assumptions of constant vessel caliber, and constant angle of insonation to the artery under scrutiny. When studied in an animal model, the Doppler derived values of $\mathrm{CBFv}$ were erroneous under conditions of low flow (30), so it seems that large insonated cerebral vessels take part in autoregulation (31), and that indices derived from $\mathrm{CBFv}$ values may underestimate true $\mathrm{CBF}$ under extreme physiologic conditions (30). The ${ }^{133} \mathrm{Xe}$ technique permits accurate measurement of global $\mathrm{CBF}$ compared with radioactive microsphere technique (14). Additionally, from an ethical perspective, measurement of CBF must not compromise the care of the infant. Each ${ }^{133} \mathrm{Xe}$ derived CBF measurement took $15 \mathrm{~min}$ to acquire caused minimal disturbance to the infant and did not materially affect the starting of treatment for the low blood pressure. The technique has limitations; rapid serial $\mathrm{CBF}$ measurements over short time intervals, less than $15 \mathrm{~min}$, cannot be measured. Furthermore, there is also a look-through phenomenon, where tissues with a high $\mathrm{CBF}$ are measured in preference to tissues with a lower CBF in the same field of interest. Lastly, there is an exposure of radiation to the infant. The dose per measurement is in the order of $5 \mu \mathrm{Sv}$, and the total dose per infant from a maximum of $5 \mathrm{CBF}$ measurements (Table 1) is approximately less than the equivalent dose from one neonatal chest $\mathrm{x}$-ray $(20 \mu \mathrm{Sv})$; this is well within national safety margins.

The $\mathrm{MAP}_{15}$-CBF reactivities of both normotensive and hypotensive infants were $1.9 \% / \mathrm{mm} \mathrm{Hg}$ change in $\mathrm{MAP}_{15}$. The value of $1.9 \% / \mathrm{mm} \mathrm{Hg}$ is similar to reactivities calculated by others $(27,28)$ in preterm infants, using different methodolo- gies. The most comparable report is an observational study undertaken by Pryds and colleges, who used the ${ }^{133} \mathrm{Xe}$ technique (13). In a group of ventilated, preterm infants they calculated a mean change in $\mathrm{CBF}$ of $0.8 \%(95 \% \mathrm{CI}-0.6 \%$ to $2.0 \%)$ per mm Hg MABP. Unlike this study, they did not categorize the infants with regard to blood pressure or induce changes in blood pressure. The $\mathrm{MAP}_{15}-\mathrm{CBF}$ reactivities calculated by our group and others imply a small change in CBF per unit change in $\mathrm{MAP}_{15}$.

While the $\mathrm{MAP}_{15}$-CBF reactivity of both the hypotensive and normotensive infants is the same, the lower confidence limit of the hypotensive infants, $0.8 \% / \mathrm{mm} \mathrm{Hg}$, is greater than zero. This is in contrast to the work of others, where the lower confidence interval includes zero $(13,27,28)$. Some authors (13) have concluded that autoregulation is preserved when the lower confidence limit encompasses zero. Therefore, one interpretation is that there are significant alterations in $\mathrm{CBF}$ with fluctuation in the $\mathrm{MAP}_{15}$ of the hypotensive infants, and that their capacity for autoregulation may be disrupted.

The $\mathrm{CO}_{2}$-CBF reactivities were $11.1 \%$ and $4.1 \% / \mathrm{KPa}$ $\mathrm{PaCO}_{2}$ in the normotensive and hypotensive infants. Assessing the reactivity of the cerebral circulation to alterations in $\mathrm{PaCO}_{2}$ within the physiologic range has fewer technical and ethical difficulties. Consequently, investigators have sought to use $\mathrm{CO}_{2}$-CBF reactivity, both qualitatively and quantitatively, in the assessment of at risk infants $(32,33)$. Others have shown that the $\mathrm{CO}_{2}$-CBF reactivity using the same methodology is $32.8 \%(95 \% \mathrm{CI} 21.8 \%$ to $44.4 \%) / \mathrm{KPa} \mathrm{PaCO}_{2}$ (13). The infants studied by Pryds and colleagues were of the same postnatal age with persistently normal cranial ultrasound scans. By contrast, others have found values that range from $32.7 \% / \mathrm{KPa}$ (28) up to $67 \% / \mathrm{KPa}(19,32)$. Consequently, a value of $11.1 \% / \mathrm{KPa}$ $\mathrm{PaCO}_{2}$ in the normotensive infants may be interpreted as an attenuated $\mathrm{CO}_{2}-\mathrm{CBF}$ reactivity. While the $\mathrm{CBF}$ still accommodates to changes in $\mathrm{CO}_{2}$, the magnitude of change is less than that seen by others. The infants presented here are of a lower gestational age than those studied previously $(12,13,19,28$, 32 ), which may part way explain the low $\mathrm{CO}_{2}$-CBF reactivity. This discrepancy may be due to maturational differences in the reactivity of the $\mathrm{CBF}$ to acute changes in $\mathrm{CO}_{2}$ (34). In contradistinction to the normotensive infants, the hypotensive infants have a $\mathrm{CO}_{2}$-CBF reactivity of $4.1 \%(95 \% \mathrm{CI}-5.0 \%$ to $14.1 \%)$. This is much lower than expected and encompasses zero within its confidence limits. Thus it would seem that the reactivity of the cerebrovasculature is greatly diminished and 
A

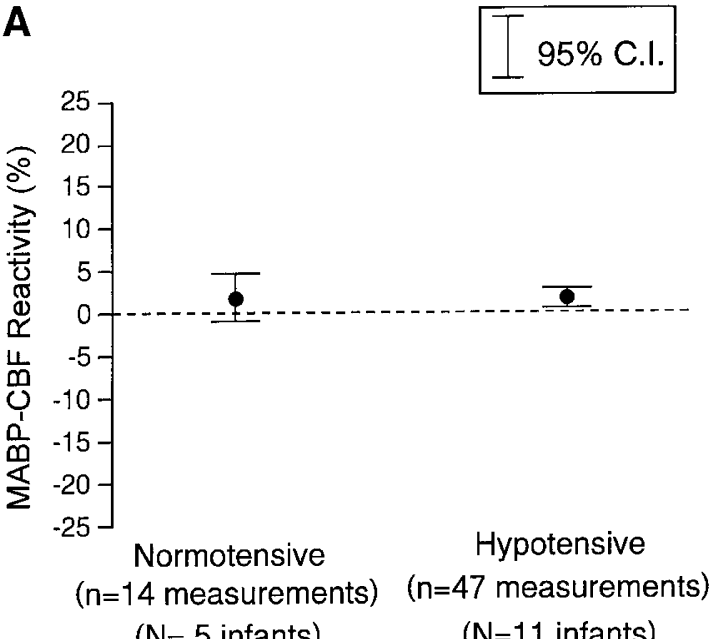

B

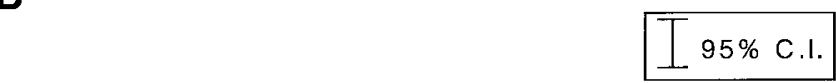

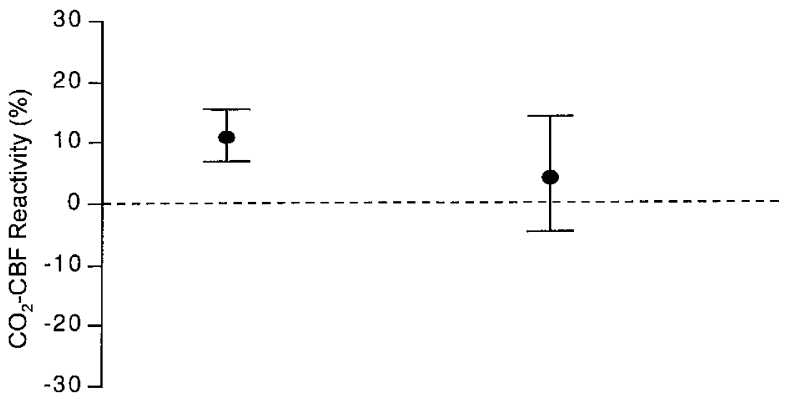

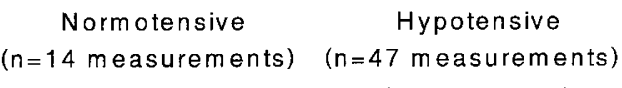

$(\mathrm{N}=5$ infants $)$

Figure 2. (A) The MABP-CBF reactivities for the normotensive and hypotensive infants is illustrated. The vertical bars represent the $95 \%$ confidence intervals. $(B)$ The $\mathrm{CO}_{2}$-CBF reactivities for the two groups studied is illustrated. The vertical bars represent the $95 \%$ confidence intervals.

possibly absent. This differential loss of autoregulation has been documented in neonatal animal studies (35). It may be that at the level of blood pressure experienced by the hypotensive group, the cerebrovasculature was able to compensate for reduced perfusion pressure by vasoconstriction but unable to accommodate for changes in $\mathrm{PaCO}_{2}$. A teleological argument could be made that it is more important to maintain an adequate $\mathrm{CBF}$ in the face of borderline perfusion pressure than to adjust to fluctuations in $\mathrm{PaCO}_{2}$. It must be born in mind however that the hypotensive infants have a lower postnatal age, and that this may contribute to the lower $\mathrm{CO}_{2}-\mathrm{CBF}$ reactivity; Pryds and colleges (24) have shown that $\mathrm{CO}_{2}-\mathrm{CBF}$ reactivity increases with postnatal age.

We have studied a simple static model of autoregulation (36), in which CBF was measured before and after a step change in another factor, either $\mathrm{MAP}_{15}$ or $\mathrm{PaCO}_{2}$. This model dose not incorporate changes in rapidly changing factors such as hematocrit, blood glucose or arterial $\mathrm{pH}$, which may be included in a more dynamic model of autoregulation $(11,26)$, but for which rapid serial measurements of CBF are necessary. Thus, we have used CBF reactivity as a surrogate measure for autoregulation. We analyzed a 15 minute average of MABP, $\mathrm{MAP}_{15}$, as an independent predictive factor on CBF because it is a routinely measured and reported $(18,37-40)$ value in neonatal intensive care units, but an alternative may be to examine the effect of systolic blood pressure on CBF; we did not collect the corresponding systolic blood pressure data. Serum glucose has an impact on CBF (41), but where this information was available the infants had near normal glucose values (Table 1) at the time of the CBF measurement. Muscle relaxation was dictated by the clinical judgment of the physician, and it may reduce the variability of CBF (42); there was no systematic bias in the use of muscle relaxation (Table 1) and is unlikely to have biased the CBF data. All the infants in the study were sedated with diamorphine infusion. The effects of opiates on cerebral blood flow in the human newborn has not been studied, but as all the subjects were given the same dosage regimen we do not believe that this influenced our overall results. Finally, infants with a hemodynamically significant PDA may have reduced CBF (43). There is a suggestion that significant flow through a PDA may reduce systemic blood flow, which may have a causative role in the etiology of intraventricular hemorrhage (44). There are no studies directly examining the effect of ductal flow on $\mathrm{CBF}$ autoregulation, but if it does have a significant effect, then the more preterm hypotensive infants are at greater risk of this further complication. There is evidence that even a large PDA does not affect EEG activity (45). Our predictive model of CBF did not include presence or absence of a hemodynamically significant PDA.

The treatment of systemic hypotension aims to improve perfusion of vital organs. A predicament for the clinician is defining hypotension due to the variety of normal values quoted for the MABP of preterm, VLBW, infants $(18,37-39)$. A widespread clinical guideline is to maintain MABP above 30 $\mathrm{mm} \mathrm{Hg}$, since MABP below this is found to be associated with intraventricular hemorrhage (46). This lower limit of $30 \mathrm{~mm}$ $\mathrm{Hg}$ has been tested and a CBF independent of MABP was found (7), due to presumed intact autoregulation. Another widely used guideline is to assume that the gestational age of the infant as the lowest acceptable MABP in $\mathrm{mm} \mathrm{Hg} \mathrm{(40).} \mathrm{Our}$ study defined hypotension using the criteria of Watkins et al. (18), whose 10th centiles for MABP are lower than either of the two former recommendations, during the early postnatal period. Watkins' definition of hypotension is supported by their finding that infants who had a MABP persistently lower than the 10th centile were found to have severe intracranial lesions (18). Our findings indicate that hypotensive infants, as defined by Watkins' criteria, have blunted or absent $\mathrm{MAP}_{15^{-}}$ CBF reactivity, and possibly absent autoregulation; this suggests that Watkins' values may be acceptable as the normal values. However we are unable to prove this in relation to the development of cerebral lesions in those infants who were hypotensive. This may well reflect the number of infants studied in the respective groups, and the reduction of intraven- 
tricular hemorrhage rates seen in the preterm population in the last $10 \mathrm{y}$.

Neonatologists have recognized for a long time that blood pressure alone is a poor reflector of tissue perfusion. It remains a challenge in neonatology to identify other physiologic measurements that can be used on a continuous basis to give a clearer indication of tissue perfusion before we are able to identify with any degree of precision the lower limit of normal blood pressure in the sick preterm infant. Our study suggests that clinicians managing blood pressure should try and avoid abrupt elevations in MABP in hypotensive infants as this may be transmitted directly to the cerebral circulation.

In conclusion, the normotensive ventilated infants described in this study appear to have near constant CBF in the face of fluctuating MABP. They also display a $\mathrm{CBF}$ that is reactive to changes in $\mathrm{PaCO}_{2}$, though to a lesser degree than expected, perhaps due to maturational changes. We speculate from the data that the hypotensive infants may have blunted MABP$\mathrm{CBF}$ autoregulation, and their $\mathrm{CBF}$-reactivity to changes in $\mathrm{PaCO}_{2}$ is very diminished and possibly absent.

Acknowledgments. We would like to thank the Special Trustees of the General Infirmary at Leeds for funding the study and Professor Gorm Greisen for helpful advice during the course of the study.

\section{REFERENCES}

1. Szymonowicz W, Yu VY, Wilson FE 1984 Antecedents of periventricular haemorrhage in infants weighing $1250 \mathrm{~g}$ or less at birth. Arch Dis Child 59:13-17

2. Trounce JQ, Shaw DE, Levene MI, Rutter N 1988 Clinical risk factors and periventricular leucomalacia. Arch Dis Child 63:17-22

3. Nowicki PT, Nankervis CA 1994 The role of the circulation in the pathogenesis of necrotizing enterocolitis. Clin Perinatol 21:219-234

4. Low JA, Froese AB, Smith JT, Galbraith RS, Sauerbrei EE, Karchmar EJ 1992 Hypotension and hypoxemia in the preterm newborn during the four days following delivery identify infants at risk of echosonographically demonstrable cerebral lesions. Clin Invest Med 15:60-65

5. Lou HC, Lassen NA, Friis-Hansen B 1977 Low cerebral blood flow in hypotensive perinatal distress. Acta Neurol Scand 56:343-352

6. Wigglesworth JS, Pape KE 1978 An integrated model for haemorrhagic and ischaemic lesions in the newborn brain. Early Hum Dev 2:179-199

7. Tyszczuk L, Meek J, Elwell C, Wyatt JS 1998 Cerebral blood flow is independent of mean arterial blood pressure in preterm infants undergoing intensive care. Pediatrics 102:337-341

8. Perlman JM, Risser R, Broyles RS 1996 Bilateral cystic periventricular leukomalacia in the premature infant: associated risk factors. Pediatrics 97:822-827

9. Weindling AM, Wilkinson AR, Cook J, Calvert SA, Fok TF, Rochefort MJ 1985 Perinatal events which precede periventricular haemorrhage and leukomalacia in the newborn. Br J Obstet Gynaecol 92:1218-1223

10. Tsuji M, Saul JP, du Plessis A, Eichenwald E, Sobh J, Crocker R, Volpe JJ 2000 Cerebral intravascular oxygenation correlates with mean arterial pressure in critically ill premature infants. Pediatrics 106:625-632

11. Boylan GB, Young K, Panerai RB, Rennie JM, Evans DH 2000 Dynamic cerebral autoregulation in sick newborn infants. Pediatr Res 48:12-17

12. Pryds O, Greisen G 1989 Effect of PaCO2 and haemoglobin concentration on day to day variation of CBF in preterm neonates. Acta Paediatr Scand Suppl 360:33-36

13. Pryds O, Greisen G, Lou H, Friis-Hansen B 1989 Heterogeneity of cerebral vasoreactivity in preterm infants supported by mechanical ventilation. J Pediatr 115:638645

14. Blomstrand S, Karlsson K, Kjellmer I 1978 Measurement of cerebral blood flow in the fetal lamb with a note on the flow-distribution. Acta Physiol Scand 103:1-8

15. Purves MJ, James IM 1969 Observations on the control of cerebral blood flow in the sheep fetus and newborn lamb. Circ Res 25:651-667

16. Greisen G, Johansen K, Ellison PH, Fredriksen PS, Mali J, Friis-Hansen B 1984 Cerebral blood flow in the newborn infant: comparison of Doppler ultrasound and 133xenon clearance. J Pediatr 104:411-418
17. Skov L, Pryds O, Greisen G 1991 Estimating cerebral blood flow in newborn infants: comparison of near infrared spectroscopy and 133Xe clearance. Pediatr Res 30:570573

18. Watkins AM, West CR, Cooke RW 1989 Blood pressure and cerebral haemorrhage and ischaemia in very low birthweight infants. Early Hum Dev 19:103-110

19. Greisen G, Trojaborg W 1987 Cerebral blood flow, PaCO2 changes, and visual evoked potentials in mechanically ventilated, preterm infants. Acta Paediatr Scand 76:394-400

20. Kleinbaum DG 1998 Applied regression analysis and other multivariable methods Duxbury Press, Pacific Grove London

21. Lassen NA 1978 Study of local cerebral blood flow. In: Dickinson CJ, Marks J (eds) Developments in Cardiovascular Medicine: The Proceedings of the Special Symposium. MTP Press, Lancaster, pp 9-14

22. Heistad DD, Kontos HA 1983 Cerebran circulation. In: Sheperd JT, Abboud FM (eds) Peripheral Circulation and Organ Blood Flow Volume. American Physiological Society, Bethesda, pp III:137-182

23. Baenziger O, Jaggi JL, Mueller AC, Morales CG, Lipp AE, Duc G, Bucher HU 1995 Regional differences of cerebral blood flow in the preterm infant. Eur J Pediat 154:919-924

24. Pryds O, Greisen G, Skov LL, Friis-Hansen B 1990 Carbon dioxide-related changes in cerebral blood volume and cerebral blood flow in mechanically ventilated preterm neonates: comparison of near infrared spectrophotometry and 133Xenon clearance. Pediatr Res 27:445-449

25. Smith EO 1987 Analysis of repeated measures designs. J Pediatr 111:723-725

26. Anthony MY, Evans DH, Levene MI 1993 Neonatal cerebral blood flow velocity responses to changes in posture. Arch Dis Child 69:304-308

27. Jorch G, Jorch N 1987 Failure of autoregulation of cerebral blood flow in neonates studied by pulsed Doppler ultrasound of the internal carotid artery. Eur J Pediatr $146: 468-472$

28. Menke J, Michel E, Rabe H, Bresser BW, Grohs B, Schmitt RM, Jorch G 1993 Simultaneous influence of blood pressure, $\mathrm{PCO} 2$, and $\mathrm{PO} 2$ on cerebral blood flow velocity in preterm infants of less than 33 weeks' gestation. Pediatr Res 34:173-177

29. Panerai RB, Kelsall AW, Rennie JM, Evans DH 1995 Estimation of critical closing pressure in the cerebral circulation of newborns. Neuropediatrics 26:168-173

30. Thoresen M, Whitelaw A 1990 Effect of acetazolamide on cerebral blood flow velocity and $\mathrm{CO} 2$ elimination in normotensive and hypotensive newborn piglets. Biol Neonate 58:200-207

31. Faraci FM, Heistad DD 1990 Regulation of large cerebral arteries and cerebral microvascular pressure. Circ Res 66:8-17

32. Levene MI, Shortland D, Gibson N, Evans DH 1988 Carbon dioxide reactivity of the cerebral circulation in extremely premature infants: effects of postnatal age and indomethacin. Pediatr Res 24:175-179

33. Fenton AC, Woods KL, Evans DH, Levene MI 1992 Cerebrovascular carbon dioxide reactivity and failure of autoregulation in preterm infants. Arch Dis Child 67:835-839

34. Wyatt JS, Edwards AD, Cope M, Delpy DT, McCormick DC, Potter A, Reynolds EO 1991 Response of cerebral blood volume to changes in arterial carbon dioxide tension in preterm and term infants. Pediatr Res 29:553-557

35. Whitelaw A, Karlsson BR, Haaland K, Dahlin I, Steen PA, Thoresen M 1991 Hypocapnia and cerebral ischaemia in hypotensive newborn piglets. Arch Dis Child 66:1110-1114

36. Panerai RB 1998 Assessment of cerebral pressure autoregulation in humans-a review of measurement methods. Physiol Meas 19:305-338

37. Lee J, Rajadurai VS, Tan KW 1999 Blood pressure standards for very low birthweight infants during the first day of life. Arch Dis Child Fetal Neonatal Ed 81:F168-170

38. Cunningham S, Symon AG, Elton RA, Zhu C, McIntosh N 1999 Intra-arterial blood pressure reference ranges, death and morbidity in very low birthweight infants during the first seven days of life. Early Hum Dev 56:151-165

39. Versmold HT, Kitterman JA, Phibbs RH, Gregory GA, Tooley WH 1981 Aortic blood pressure during the first 12 hours of life in infants with birth weight 610 to 4,220 grams. Pediatrics 67:607-613

40. 1992 Development of audit measures and guidelines for good practice in the management of neonatal respiratory distress syndrome. Report of a Joint Working Group of the British Association of Perinatal Medicine and the Research Unit of the Royal College of Physicians. Arch Dis Child 67:1221-1227

41. Pryds O, Greisen G, Friis-Hansen B 1988 Compensatory increase of CBF in preterm infants during hypoglycaemia. Acta Paediatr Scand 77:632-637

42. Colditz PB, Williams GL, Berry AB, Symonds PJ 1989 Variability of Doppler flow velocity and cerebral perfusion pressure is reduced in the neonate by sedation and neuromuscular blockade. Aust Paediatr J 25:171-173

43. Weir FJ, Ohlsson A, Myhr TL, Fong K, Ryan ML 1999 A patent ductus arteriosus is associated with reduced middle cerebral artery blood flow velocity. Eur J Pediatr 158:484-487

44. Kluckow M, Evans N 2000 Low superior vena cava flow and intraventricular haemorrhage in preterm infants. Arch Dis Child Fetal Neonatal Ed 82:F188-194

45. Kurtis PS, Rosenkrantz TS, Zalneraitis EL 1995 Cerebral blood flow and EEG changes in preterm infants with patent ductus arteriosus. Pediatr Neurol 12:114-119

46. Miall-Allen VM, de Vries LS, Whitelaw AG 1987 Mean arterial blood pressure and neonatal cerebral lesions. Arch Dis Child 62:1068-1069 